\title{
MOVIMENTO SOCIAL EM VITÓRIA DA CONQUISTA: EDUCAÇÃO E RELIGIÃO A PARTIR DA SEGUNDA METADE DO SÉCULO XX
}

\author{
Ruy Hermann Araújo Medeiros \\ ruy-medeiros@bol.com.br \\ UESB \\ Sérgio Eduardo Montes Castanho \\ castanho@dglnet.com.br \\ UNICAMP/UESB
}

\section{RESUMO}

Apresentamos experiências de organização religiosa católica denominada "Comunidades Eclesiais de Base" (CEBs), surgida no Brasil a partir dos anos de 1950. Em Vitória da Conquista, as CEBs nascem em torno de 1968, e se desenvolvem pela cidade e por outras da diocese de Vitória da Conquista e zona rural. A pesquisa questiona se as CEBs conquistenses atenderam apenas a interesses da propagação religiosa, se podem as práticas educativas desenvolvidas pelas CEBs ser consideradas apenas discurso religioso face à troca de experiências que promovem entre seus integrantes e outros movimentos e se há algum ponto de convergência entre a teologia preferencial das CEBs e conhecimento crítico sobre a realidade regional. Questiona ainda se o movimento social protagonizado pelas CEBs teve impacto nas lutas pelo poder e se contribuíram com a sua influência para sua educação regular. Na presente pesquisa, os autores evidenciam seu afastamento de duas perspectivas metodológicas: aquela que reduz o método a conjunto de regras, que marca profunda tradição, e aqueloutra que nega o método, por considerar que o empreendimento científico é anárquico. Quanto à perspectiva reducionista de método a conjunto de regras, deve-se lembrar com frequência que o cientista estabelece aquilo que comporta veracidade, não é estratégia de determinada ação.

Palavras-Chave: Igreja; Comunidades Eclesiais de Base; Educação Religiosa.

\section{SOCIAL MOVEMENT IN VITORIA DA CONQUISTA: EDUCATION AND RELIGION FROM THE SECOND HALF OF XX CENTURY}

\section{ABSTRACT}

Some experiences are presented from a Catholic religious organization called Basic Ecclesial Communities (BECs) that emerged in Brazil since the 1950s. In Vitória da Conquista, the BECs appeared around 1968, and developed around the city and other dioceses of Vitoria da Conquista and countryside. The research asks if the BECs in Vitória da Conquista attended only interests about spread religious, and if the educational practices developed by the BECs can be considered only as a religious discourse because there were exchange experiences promoted by its members and other groups and if there is a convergence point between the preferential theology from BECs and the critical knowledge about the regional reality. The research also considers whether the social movement played by BECs had impact on power disputes and contributed their influence to their regular education. In this research, the author demonstrates his withdrawal about two methodological perspectives: one that reduces the method as a set of rules, which demonstrates deep tradition, and one that denies the method, considering that the scientific achievement is anarchic. Regarding the reductionist perspective of the method as a set of rules, one should remember that the scientist often establishes what holds truth and is not a strategy based on certain action.

Keywords: Catholic Church. Basic Ecclesial Communities. Religious Education 


\section{Introdução}

A partir da segunda metade da década de 1960 desenvolveram-se experiências de organização e vida religiosa no seio da população católica com o nome de Comunidades Eclesiais de Base, que aqui abreviadamente serão denominadas CEBs. Há quem identifique o surgimento dessas organizações religiosas a partir dos anos 50 do século passado (BOFF, 1974, p.57). Leonardo Boff, estudioso das CEBs, semanticamente delimita-as entendendo-as como "agrupamentos restritos, onde vigem relações primárias, isto é, afetivas, nominais e interpessoais, cristãs, formadas pelas camadas pobres da sociedade" (1974, p.51).

No entanto, a determinação semântica não é suficiente para defini-las. O próprio autor mostra uma série de questões que envolvem as CEBs: tensões com estruturas tradicionais da Igreja, participação política, renovação teológica, estratégia pastoral, etc.

Conforme estudo de Ivana Silveira, as análises históricas e documentais sobre o catolicismo em meados do século XX não podem deixar de citar o Concílio Vaticano II, um dos acontecimentos mais importantes de todos os tempos no campo do catolicismo e que revolucionou ${ }^{1}$ muitos dos parâmetros educativos dessa religião:

O Concílio efetivou-se entre os anos de 1962 e 1965, a mais de 100 anos após o Concílio Vaticano I - realizado entre 1869-1870. Este último alcançou uma durabilidade de 18 anos, mas não se ressaltou qualquer destaque de participação do episcopado da América Latina, posto que unicamente demarcou-se a presença dos episcopados italiano, francês, alemão e espanhol. Já no Concílio Vaticano II a presença do episcopado latino-americano delimitou-se de forma forte e maciça (SILVEIRA, 2012, p. 136).

Nas palavras da autora, é notório considerar que, bem anteriormente ao acontecimento do Vaticano II, a Igreja Católica já vinha desenvolvendo algumas ações pastorais militantes que merecem destaque, especialmente por entre as áreas rurais ${ }^{2}$. Dentre elas, as CEBs - Comunidades Eclesiais de Base, que nasceram das camadas mais pobres e marginalizadas do campo, das periferias das cidades e, mais posteriormente, dos bairros operários.

\section{Comunidades Eclesiais de Base - CEBs}

Frei Beto (1985, p.16-17) definiu as CEBs da seguinte forma:

São comunidades, por que reúnem pessoas que têm a mesma fé, pertencem à mesma igreja e moram na mesma região. Motivadas pela fé, essas pessoas vivem uma comum-união em torno de seus problemas de sobrevivência, de moradia, de lutas por melhores condições de vida e de anseios e esperanças libertadoras. São eclesiais, porque congregadas na Igreja, como núcleos básicos de comunidades de fé. São de base, porque integradas por pessoas que trabalham com as próprias mãos (classes populares): donas de casa, operários, subempregados, aposentados, 
jovens e empregados dos setores de serviço, na periferia urbana; na zona rural, assalariados agrícolas, posseiros, pequenos proprietários, arrendatários, peões e seus familiares.

As CEBs veiculavam a doutrina social da Igreja, mas fixaram-se em aspectos mais inovadores dentro daquelas decorrentes das conclusões do Vaticano II (1962), das conclusões de Medellín (1968) e de Puebla (1979). O aprofundamento dessas conclusões levou à densificação doutrinária que recepcionou aspectos mais avançados e acolheu outros, inclusive decorrentes do diálogo com os marxistas. Muitos teólogos entenderam que a luta pela libertação era a exigência fundamental do Evangelho e que isso impõe uma tomada de posição, politicamente, e uma "opção preferencial pelos pobres".

As CEBs, na perspectiva da Teologia da Libertação, foram vistas como cristalização de forças dentro da história da Igreja: "Analiticamente considerando, o fenômeno das CEBs cristaliza três forças históricas: a utopia dos primeiros missionários, a emergência do laicato e a irrupção política dos pobres." (BOFF, 1992, p. 131).

Textos como os de Gustavo Gutierrez, reunidos em A Força Histórica dos Pobres (1981), Enfoques Materialistas de Bíblia, de Michel Clévenot (1987), Caminhos de Libertação Latino - Americana, de Enrique Dussel (1980; 1986), Diálogo Posto à Prova, de Mário Gozzini (1968), Cristãos e Marxistas, de G. Cottier (1968), e outros escritos de uma multidão de teólogos, dentre os quais Claúdio Perani (2009), alimentaram e tentaram direcionar a discussão religiosa em confronto com a realidade dos oprimidos.

\section{As Comunidades Eclesiais de Base em Vitória da Conquista.}

Em Vitória da Conquista, as CEBs nascem a partir de 1968, num bairro então periférico da cidade: Pedrinhas, em casa de um aguadeiro, e se desenvolve pela cidade e por outras da diocese de Vitória da Conquista e zona rural.

A iniciativa, com moderada permissão do bispo diocesano, Dom Climério Almeida, partiu do padre Luís Mosconi, italiano, auxiliado por professoras que haviam trabalhado no MEB - Movimento de Educação de Base. Poucos escritos há sobre as CEBs em Vitória da Conquista. Pode-se mencionar um livro: Edivanda:uma vida de fé e de muitas lutas (MOSCONI, 2002), que é conjunto de textos de vários autores sobre a trajetória de vida da principal educadora das CEBs, contendo informações sobre essas.

Também diversos números da Revista do CEAS trazem artigos sobre movimentos, questões populares e CEBs. Arquivos da Arquidiocese de Vitória da Conquista, especialmente o livro de tombo da Paróquia de Nossa Senhora das Graças e comissão rural diocesana, documentam eventos promovidos ou com a participação de referidas comunidades. Ademais, há registros da atuação daquelas no jornal mimeografado $O$ Animador, publicado após cada encontro de "animadores" das comunidades, além de informações esparsas.

A presente pesquisa, ainda em andamento, busca examinar a formação, as práticas políticas e educativas das Comunidades Eclesiais de Base (CEBs), em Vitória da Conquista e em sua região geográfica (Diocese de Vitória da Conquista), à luz dos conhecimentos proporcionados pela história, pelos campos teóricos da memória, da política e da pedagogia.

Em Vitória da Conquista desenvolveu-se, como foi dito, a partir de 1968, a organização e forte atuação de Comunidades Eclesiais de Base as quais refluíram e deixaram de ter importância no contexto político-social da região a partir de 1982. Como 
em outras regiões, as CEBs da região conquistense tiveram grande impacto na sociedade. Além de organizar setores populares, por meio das CEBs, a Igreja Católica aí desenvolveu práticas políticas e educacionais. Passados alguns anos de seu apogeu, é necessário que se promova estudo sobre a mencionada forma organizativa, colhendo suas experiências e buscando entender com profundidade o seu sentido, pois protagonizaram fatos importantes e desenvolveram educação não regular, devendo-se dizer que esse tipo de educação não tem sido estudado como deveria.

Pode-se, de antemão, dizer que as CEBs filiam-se a duas forças: uma, o esforço do Concílio Vaticano II em direcionar o discurso da Igreja no sentido de que este pudesse abranger novas realidades do mundo: a luta dos povos oprimidos, os conflitos de classe, as desigualdades; outra, a própria necessidade de organização dos trabalhadores do campo e da cidade, dentro de especificidades nacionais e locais. A primeira dessas forças tem, evidentemente, profundos condicionamentos históricos e sociais. A luta de classes que se desenvolvia, a desigualdade entre as nações, a guerra fria, os conflitos ideológicos, a percepção dos religiosos de que perdiam ou perderiam espaço para esforços revolucionários ou para opções de fé fundamentalistas.

O Brasil, onde movimentos sociais se desenvolviam no campo e na cidade, presenciou a intervenção brutal de militares e civis, representada pelo golpe de 1964 e seus governos. Os movimentos foram desarticulados, líderes foram presos ou buscaram clandestinidade e exílio. Amplamente favorável ao golpe militar, a Igreja Católica gradativamente foi se afastando do apoio aos governos da ditadura.

Pontual e lentamente aconteceu esse conflituoso afastamento. Difícil equacioná-lo igualmente. Entre a conservação da ordem, fator sempre grato à Igreja, e a percepção de que havia vítimas em número cada vez maior, sem voz, entre familiares que adotavam os ritos eclesiais católicos, e de que a pressão para seu pronunciamento se avolumava, em relação à ditadura, a Igreja Católica passa a ouvir pessoas que tinham relação com vítimas do poder e essas próprias.

Mas outro condicionamento nessa lenta tomada de posição não pode ser esquecido: a ditadura militar esvaziava, em sua persecução de ocupar todos os espaços, ações necessárias ao desenvolvimento das atividades do clero católico, assim como tentava esvaziar de conteúdo dinâmico a cultura, as artes e a educação. Enfim, tratava-se da questão da liberdade, que a ditadura compreendia apenas como sua própria liberdade.

As Comunidades Eclesiais de Base buscavam promover a conscientização de pessoas e do grupo, entendendo-a como o alcance do estado de conhecimento da realidade contraditória da sociedade e consequente necessidade de superação das condições políticosociais opressivas, provocando viabilização de ações em torno de questões concretas.

Uma vez que tinham como marco a militância à luz da fé, é necessário saber se aquelas comunidades conseguiam solucionar algumas questões que se encontram no cerne de toda atividade educativa que se propõe inserir a pessoa em seu contexto, porém, sob pressuposto de um dado prévio, no caso daquelas, um corpo teológico.

Em princípio, pode-se responder que o corpo teológico de fundo - a doutrina da Teologia da Libertação - tem a marca da alienação e, portanto, não oferece caminho para a atuação autônoma do grupo, como pretendiam muitos católicos, nem para a profunda conscientização do caráter contraditório do mundo e das condições de superação dos fatores opressivos.

No entanto, para alguns, a organização das pessoas e sua conscientização era passo fundamental, cabendo aos próprios oprimidos a escolha de sua posterior evolução. Outra questão era a do método de análise: padres comprometidos com a organização e militância das Comunidades Eclesiais de Base pretendiam que sua análise da sociedade radicava no 
pensamento marxista. Ora, esse não propõe secionamento entre método e saber, de forma a preservar (como queriam os padres militantes das CEBs) um corpo doutrinário que inclui o divino e que os marxistas consideram alienação/alienante, na análise do corpo social, que só inclui o divino como superestrutura, para os últimos, e que para os primeiros (teólogos) é um dado não descartável do mundo.

Incluir ou excluir Deus do mundo é questão relevante para o debate, como tantas vezes foi acentuado, por cristãos e marxistas. Dessa intransponibilidade resultou que muitas vezes na atuação colaborativa a questão ficasse em suspenso.

A educação das CEBs encontrava um limiar de "difícil" superação ou de "impossível" superação: não bastava o diálogo com os comunistas, pois os pressupostos teóricos destes eram infungíveis com a teologia. Mas, por outro lado, ambos estavam interessados na transformação do status quo. A leitura da opção preferencial pelos pobres se radicalizava entre alguns padres da Igreja e, à medida que isso ocorria, o diálogo com os marxistas interessava a ambos, especialmente no contexto da ditadura militar com toda sua carga de instrumentos de manutenção autoritária da ordem estabelecida.

Como resolver, no plano teórico, a tendência forte de aproximação entre marxistas e padres vinculados à Teologia Libertação, que se dava na prática social, com vistas a definir se a fé terminaria por impor freios à pretendida liberação do homem? Isso diz respeito igualmente ao estatuto da educação: a perspectiva de viver a fé, diante dos desafios da pretendida transformação social, poderia conviver com a ideia de autonomia, diante do dado prévio que é a fé?

Isso importa ainda mais quando se sabe que, para muitos padres, envolvidos com as CEBs, a própria fé/religião é uma forma de conhecimento. A análise dessa relação educação/fé precisa ser feita, pois esse dístico perpassa fortemente a história e, mesmo diante do estado laico, com as noções de multiculturalismo, convivência etc., aquela relação se repõe constantemente.

Educação-ciência, educação-fé, educação-conservação, educação - transformação, educação - submissão, educação - autonomia são conexões com que se debatem a política de ensino e as teorias pedagógicas. O estudo de experiência, fora dos limites das salas de aula e de sua regularidade (ensinos não regulares), traz luz para o conhecimento dessas mencionadas relações.

A pesquisa e o texto decorrente deverão evidenciar, diante da experiência vivida pelas Comunidades Eclesiais, possíveis contribuições para o estudo da relação fé/religião x educação, que extrapolem $\mathrm{o}$ mero problema da institucionalidade $\mathrm{x}$ educação religiosa/educação laica.

O desenvolvimento das CEBs no Brasil foi fator importante de aglutinação de esforços e de direcionamento de militância. Em Vitória da Conquista e região, no campo e na cidade, foram organizadas comunidades eclesiais que tiveram impacto considerável na vida política de referido espaço. A luta pela terra, a proteção de posseiros, a greve dos trabalhadores na cultura do café, as ocupações do solo urbano, a luta sindical, dentre outros, são eventos patrocinados pelas CEBs em colaboração com pessoas de esquerda. Cumpre examiná-las, em suas diversas determinações, no contexto espaço-temporal de seu surgimento, na parte e na totalidade, à luz da história e dos conhecimentos alcançados pelos estudos da memória, da política e da educação.

Os estudos sobre a educação e sua história têm preferencialmente analisado experiências didático-pedagógicas, pedagogias, políticas públicas, currículos, escolas e professores. E, nesse âmbito, os avanços têm sido marcantes, inclusive no Brasil ${ }^{3}$.

No entanto, até mesmo porque exigências políticas de defesa do ensino público, gratuito e de qualidade impuseram aos estudiosos trabalhos teóricos a partir da análise da 
institucionalidade, não se procurou verificar se o ensino não regular oferecia qualquer contribuição para a compreensão de conteúdos importantes, tais como a relação autonomia - alienação, militância política e educação, conflitos entre métodos de análise e propósitos dos objetos educacionais, etc.

Também pode-se constatar que o debate entre ensino laico e ensino religioso aparece na historiografia da educação, como conflito entre Estado e Igreja no âmbito da educação, passando ao largo da convergência (insuspeita para alguns) entre os dois pontos de vista: ensino preponderantemente religioso, ensino laico.

Ora, muito do ensino autodefinido como laico tem conteúdo religioso e não exclui opção de fé de legisladores, de autoridades, de professores, etc. O exame de livros escolares demonstra persistência de conteúdos ideologicamente religiosos, mágicos. Sob esse aspecto, também a historiografia rendeu-se ao debate entre religiosos e laicistas, em especial ao caráter do Estado vinculado ao tipo de ensino e, por conseguinte, isso tem importância suficiente para constar da historiografia da educação. Trata-se de saber como o estado laico prevê educação a um só tempo laica e religiosa, privilegiando, aí, o cristianismo, deixando outras crenças sem menção.

No entanto, há práticas educativas, não regulares, que devem constar na história da educação e que importam em adoção de ideias pedagógicas que merecem a atenção do estudioso, por implicarem ora o caráter conservador da educação, ora o caráter emancipatório desta, na contradição que marca as práticas educativas, os conteúdos, os currículos e as motivações.

Nesse sentido, a análise a partir de experiência vivida, histórica, do trabalho educativo desenvolvido pelas Comunidades Eclesiais de Base, justifica-se: afinal, aí se desenvolveram atividades que importaram em organização, lutas, considerações teóricas sobre o ensino extraescolar. Podem-se examinar os limites (ou não) de ensino que pretendia inculcar autonomia, diante da prevalência de um parâmetro maior, "a partir da fé”.

O estudo das Comunidades Eclesiais de Base, a partir de suas práticas, permite visualizar um momento do movimento popular rico de buscas e envolvido por contradições vividas no seu contexto e em seu interior.

A análise do transcurso histórico daquelas comunidades coloca o estudioso diante de problemas que são problemas da educação: pode esta possuir caráter emancipatório? A educação pública tem sido efetivamente público-republicana? As experiências populares servem para compreender limites da educação sistemática, regular? Ora, a ideia de colar a educação à concretude da vida, presente na obra de vários pedagogos (educação para a vida), pressupõe o estudo de como isso é buscado pelos movimentos sociais, pressupõe parâmetros diferentes, se veiculado em propostas do Estado, interpenetrado em esforços de agentes não estatais.

O trabalho educativo das Comunidades Eclesiais de Base, componente necessário da atuação destas, tem relevo suficiente para ser objeto de indagações de estudo em nível de doutorado. No trabalho educativo daquelas colocam-se problemas que interessam aos educadores: autonomia e alienação, liberdade e opressão.

Em Vitória da Conquista, entre os anos de 1968 e 1982, Comunidades Eclesiais de Base foram organizadas e tiveram forte atuação. Defrontaram-se e pretenderam responder questões que interessam à educação e à sua história. Examinar interdisciplinarmente aquela atuação das CEBs, priorizando seu conteúdo prático e educativo, à luz da história, dos conhecimentos da Pedagogia, dos saberes alcançados pelo campo da memória e propor equacionamento teórico das questões postas por aquelas, em seu momento, inclusive relação educação-liberdade-religião, tem relevo para o conhecimento - a partir de dados 
concretos - da educação em vários de seus aspectos, inclusive conflito entre autonomia e alienação.

Embora o pesquisador entenda que o estudo de uma realidade importa em responder sobre ela, sendo despiciendo arrolar perguntas que surgem no decorrer do próprio estudo e desafiam respostas, não se exime de apontar objetivos antecipados nessa fase, por exigência das práticas usuais nos meios acadêmicos e considerando que algum norteamento deve ser apontado para a avaliação da importância do próprio objeto quanto ao recorte pretendido.

O seguinte rol de questões norteia a presente busca: a) em seu contexto regional as CEBs da diocese conquistense atenderam apenas a interesses da propagação religiosa? b) Podem as práticas educativas desenvolvidas pelas CEBs ser consideradas apenas discurso religioso face à troca de experiências que promove entre seus integrantes e outros movimentos? c) Há algum ponto de convergência entre a teologia preferencial das CEBs (Teologia da Libertação) e o conhecimento crítico sobre a realidade regional? d) Que fatores determinaram o refluxo social das CEBs na região de Vitória da Conquista? e) $\mathrm{O}$ movimento social protagonizado pelas CEBs teve impacto nas lutas pelo poder? f) Contribuíram as CEBs com a sua influência para sua educação regular?

\section{Do Método}

$\mathrm{Na}$ presente pesquisa, os autores evidenciam seu afastamento de duas perspectivas metodológicas: aquela que reduz o método a conjunto de regras, que marca profunda tradição, e aqueloutra que nega o método, por considerar que o empreendimento científico é anárquico. Quanto à perspectiva reducionista de método a conjunto de regras, deve-se lembrar com frequência que o cientista estabelece aquilo que comporta veracidade, não é estratégia de determinada ação. Já quanto à negativa do método, não se pode afastar, para negar a negativa, a assertiva de que haverá sempre o olhar crítico para analisar, dentro de inúmeros dados e aspectos, a complexa atuação das mulheres e dos homens, a multiplicidade de eventos e os instrumentos dos diversos saberes.

Método é mais que pesquisa, pressupõe concepção sobre o saber, sobre a produção do conhecimento que supera o senso comum, pois quer alcançar a cientificidade, ao dizer sobre o objeto.

A postura do observador consciente, que age com um objetivo, uma intenção, importa em reconstruir gradual e progressivamente o concreto, tornando-o pensar sobre a realidade, em esforço que alcança a síntese. Tem, de início, uma abstração, mas apreende a realidade de seu objeto, pensa-a, construindo-a na inteligência, e sintetiza. Esta será síntese multideterminada.

Nesse saber-método, a realidade objetiva x mundo material, é sempre considerada. O ângulo de visão não se funda em abstrações, é haurido em observações das condições reais. O homem e a mulher estão situados, interagem, produzem história dentro de um contexto. Diante da realidade, mulheres e homens sofrem os mais diversos condicionamentos e limitações, mas criam, fazem a história e a sua imaginação, são capazes de entender o meio e explicá-lo em síntese.

Realidade multidiversa, contraditória e em movimento, impõe que isso mesmo seja considerado em qualquer análise. Há entrechoques sociais, há contrárias concepções, há contexto e a inteligência não se divorcia disso (CASTANHO, 2010). Como quer superar (caso do pensador e da pensadora) o conhecimento vulgar ou o simples empirismo, entende que homens e mulheres adotam concepções dominantes, são sujeitos à alienação e aos 
efeitos da reificação. Por isso, buscam criticar o saber posto como um dos pressupostos do saber científico. Nesse esforço muitos instrumentos são utilizados: são os instrumentos de seu tempo, sem exclusão da busca de outros, que inventam. Nisso o cientista tem conhecimento que deve solucionar a relação entre o todo e as partes e verificar mediações adequadas.

A presente análise tenta evitar o approach de história das representações e as meras exterioridades para alcançar-se radicalmente essência e síntese. Entende-se que se deve evitar a história fantasiada, que continua a despontar com furos de cientificidade. Castanho indica:

Vê-se, por aí, que há uma história fantasiada, envolta na roupagem dos princípios, das ideias, das categorias imaginadas a partir de certos sinais exteriores, e há uma história real, fruto de uma penosa pesquisa das condições de existência dos homens de cada período. Essa história, a de Marx, não a de Proudhon, apesar de sua aparência é a mais humana. Não obstante ligar fortemente o homem à natureza na criação das condições materiais de sua existência e, nesse sentido, ter ar de naturalista, essa história é radicalmente humanista: é a única que apresenta realmente os homens, nas palavras de Marx, "como autores e atores de seu próprio drama”. (2010, p. 19).

No entanto, além da análise da realidade concreta do objeto, devem ser observados cuidados quanto à análise de trabalhos escritos para perceber sua essência (ir além da aparência, da representação e da intencionalidade) de forma crítica, níveis ideológicos que o informam, ou de que possam se revestir, inserindo-os em contextos, quer de outras fontes, quer no âmbito de sociedade.

A crítica das fontes considera autoria, diretrizes de pensamento e práticas pedagógicas a que se referem. O sentido da fonte documental tem sido estabelecido criticamente e não dispensa seu relacionamento com documentos anteriores e posteriores.

No caso do objeto em questão, tem sido possível estabelecer série, especialmente quanto a publicações produzidas pelas e para as Comunidades Eclesiais de Base; principalmente tendo em vista a presença de práticas educativas nas CEBs que derivam de Paulo Freire.

Como foi declarado inicialmente, apresentamos experiências de organização religiosa católica denominada "Comunidades Eclesiais de Base" (CEBs), surgida no Brasil a partir dos anos de 1950. A Literatura pertinente já foi revisada e evidenciou que em Vitória da Conquista, entre os anos de 1968 e 1982, Comunidades Eclesiais de Base foram organizadas e tiveram forte atuação, no âmbito da diocese e suas múltiplas paróquias. As entrevistas até então realizadas apontam para comunidades vivazes que se defrontaram e pretenderam responder questões que interessam à educação, à religião e à história. 


\section{Referências}

BOFF, Clodovis. Comunidade eclesial: comunidade política - ensaios de eclesiologia política. Petrópolis: Vozes, 1974.

BOFF, Leonardo. América Latina: da conquista à nova evangelização. 3. ed. São Paulo: Ática, 1992.

CASTANHO, Sérgio. Teoria da história e história da educação: por uma história cultural não culturalista. Campinas: Autores Associados, 2010.

CLÉVENOT, Michel. Enfoques materialistas de Bíblia. 2. ed. São Paulo: Paz e Terra, 1987.

COTTIER, G. Cristãos e marxistas: diálogo com Roger Garaudy. Trad. Mario T. Alves. Porto e Rio de Janeiro: Brasília Editora e Paz e Terra, 1968.

DUSSEL Enrique. História da Igreja latino-americana (1930 a 1985). São Paulo: Paulus, 1989.

GOZZINI, Mario e outros. Diálogo posto à prova. Rio de Janeiro: Paz e Terra, 1968.

GUTIERREZ, Gustavo. A força histórica dos pobres. Petrópolis: Vozes, 1981.

MOSCONI, Luís (org.). Edivanda: uma vida de fé e de muitas lutas, São Paulo: Parábola, 2002.

PERANI, Claudio. Igreja popular, movimentos sociais e Teologia da Libertação. Salvador: Centro de Estudos e Ação social, 2009.

SILVEIRA, Ivana Teixeira. Ação pastoral e educação: uma visão histórica e documental (1961-1992). In: CASIMIRO, Ana Palmira B. S., AGUIAR, Itamar Pereira de. Educação e religião. Campinas, SP: Editora Alínea, 2012.

\section{Notas}

1 Esse acontecimento histórico revolucionou muitos dos parâmetros educativos e litúrgicos na prática do catolicismo, mediante os quais pode-se citar: os sacerdotes voltam-se para a frente do público de fiéis nas celebrações; o latim é retirado como língua oficial da liturgia e substituído pela língua local; desmistificou-se a divinização dos sacerdotes; os cantos gregorianos são abandonados e substituídos por instrumentos musicais modernos como o violão e cantos mais populares (SILVEIRA, 2012).

2 Além da CEB, foram fundados os seguintes movimentos: O Movimento de Educação de Base (MEB), projeto educacional inspirado na Teologia da Libertação e lançado pela Igreja Católica, junto às comunidades rurais, mediante o qual se implantaram as chamadas "escolas radiofônicas", isto é, atividades na área da alfabetização, assessoradas pelos meios de comunicação de massa e procurando colocar o aluno e o seu meio cultural como sujeito deste processo educacional; A Ação Católica (AC), apoiada nos estudos das Ciências Humanas, atuou em diferentes âmbitos da sociedade civil, atraindo a execução de trabalhos de treinamento e acompanhamento com lideranças sindicais. Dela foram criados vários subgrupos de Juventude: Juventude 
Agrária Católica (JAC); Juventude Estudantil (JEC); Juventude Independente (JIC); Juventude Operária (JOC); Juventude Universitária (JUC). A AC subsidiou grande parte dos movimentos populares no período militar dos anos 60,70, 80, fazendo, assim, despontar grandes lideranças a exemplo dos movimentos estudantis, como a UNE (SILVEIRA, 2012, p.139-140).

${ }^{3}$ Segundo Silveira (2012) a ação pastoral é também educativa, firmada em um sistema de práticas e de representações em que leigos e clero concretizam nos âmbitos da Igreja Católica. Além de elaborarem os rituais formais religiosos, estes agentes católicos estão inseridos em campanhas assistencialistas, reuniões de planejamento, estratégias de ação, festividades que os firmam diante de determinados processos socioeducativos. Doravante, estes processos socioeducativos da Ação Pastoral consolidam a instituição da Igreja Católica.

Recebido em out/2013

Aprovado em out $/ 2013$ 